\title{
Sediment properties in the fluvial and estuarine environments of the Mekong River
}

\author{
Hoang-Anh $\mathrm{Le}^{1,2^{*}}$, Nicolas Gratiot ${ }^{2,3}$, William Santini ${ }^{3}$, Olivier Ribolzi ${ }^{4}$, Sandra \\ Soares-Frazao ${ }^{l}$, and Eric Deleersnijder ${ }^{5,6}$ \\ ${ }^{1}$ Civil and Environmental Engineering, Institute of Mechanics, Materials and Civil Engineering \\ (IMMC), Université catholique de Louvain, Place du Levant 1, B-1348 Louvain - la - Neuve, \\ Belgium \\ ${ }^{2}$ Asian Research Center on Water (CARE-Rescif), Ho Chi Minh City University of Technology, \\ Block B7, 268 Ly Thuong Kiet Street, District 10, Ho Chi Minh City, Vietnam \\ ${ }^{3}$ Le laboratoire Géosciences Environnement Toulouse, Institut de Recherche pour le Développement, \\ 14 Avenue Edouard Belin, 31400 Toulouse, France \\ ${ }^{4}$ IRD, Géosciences Environnement Toulouse (GET), Université Paul Sabatier, Toulouse, France \\ ${ }^{5}$ Université catholique de Louvain, Institute of Mechanics, Materials and Civil Engineering (IMMC) \\ \& Earth and Life Institute (ELI), 4 avenue Georges Lemaître, B-1348 Louvain-la-Neuve, Belgium
}

${ }^{6}$ Delft University of Technology, Delft Institute of Applied Mathematics (DIAM), Van Mourik Broekmanweg 6, 2628XE Delft, The Netherlands

\begin{abstract}
The Mekong river, located in Southeast Asia, is one of the largest rivers in the world. It is facing serious problems related to sediment transport, e.g. the reduction of sediment volume supply to the delta and estuary. This study focuses on the physical properties of suspended particles in the upstream fluvial section (Luang Prabang, Laos) and in the region of tidal influence (Song Hau estuary, Vietnam). These sites are respectively the upper and lower limits of the Lower Mekong River (LMR), which are experiencing contrasted transport modes. The main objective of this study is to quantify the proportion of inert sand and of cohesive particles in the water through comprehensive measurements of particle size, settling velocity and flocculation in the water column. Two field campaigns were undertaken in the summer monsoon season. The results point out the predominance of flocculi, with sizes of $18 \pm 5 \mu \mathrm{m}$ in the fluvial environment and $15 \pm 5 \mu \mathrm{m}$ in the estuary and the similarities in patterns, mixture of sand $(12 \pm 5 \%)$ and mud $(88 \pm 5 \%)$. They also provide a statistically representative set of suspended particle populations in the upstream and downstream regions that could be used for improving numerical models.
\end{abstract}

\footnotetext{
* Corresponding author: anh.le@uclouvain.be
} 


\section{Introduction}

The Mekong River is the $10^{\text {th }}$ longest river in the world with a length of $4909 \mathrm{~km}$ and a basin area of $795,000 \mathrm{~km}^{2}$. Its mean annual flow is approx. $475 \mathrm{~km}^{3}$, i.e. the sixth largest in the world. The river originates from the Tibetan Plateau (China) with an elevation of more than $5000 \mathrm{~m}$ above sea level, then passes through a variety of geomorphological and climatic systems and ends in the huge fertile delta of Vietnam before discharging into the South East Sea of Vietnam [1]. According to [2], water and sediment discharge from land to ocean is mostly controlled by tropical cyclones, with a distinct wet season (May October) and a dry season (November - April) [1]. Under human pressures and climate change, the river is facing many serious issues relating to sediment transport. In addition, the construction of large hydropower dams in the upstream Mekong may further reduce the sediment discharge into the floodplain and estuaries, which has already decreased from about $160 \mathrm{Mt} / \mathrm{yr}$ in 1983 [3] to $87.4 \pm 28.7 \mathrm{Mt} / \mathrm{yr}$ in 2005 [2, 4]. Therefore, it is necessary to conduct thorough studies on sediment transport and erosion/deposition in the whole basin, where the physical properties of sediment particles play an essential role.

This study focuses on the Lower Mekong Basin (LMB) system with one site in the upper fluvial environment (Fig. 1a) and another in the lower estuarine environment (Fig. 1b). Previous studies indicated that the upper section was dominated by two populations: silt, with a diameter of $10-20 \mu \mathrm{m}$, and sand, with a diameter of $70-200 \mu \mathrm{m}$, accounting for $78 \%$ and $22 \%$ of the total particle load, respectively [5]. In the estuary, flocculated fine particles dominate. The observed floc size was $30-40 \mu \mathrm{m}$, constituting $60-80 \%$ of the total sediment load in high flow season. However, in the low flow season, the floc size increased to $50-200 \mu \mathrm{m}$, accounting for $70-80 \%$ of the total volume $[6,7]$. This phenomenon is a consequence of flocculation processes.

Flocculation is a dynamically active process, which directly depends on interactions between particles and the surrounding fluid [8]. Conceptually, flocculation develops into hierarchical structures, namely primary particles, flocculi, microflocs and macroflocs. Primary particles mainly consist of fine particles with sizes of $0-10 \mu \mathrm{m}$, which are organic and inorganic particles. Flocculi's size is of the order of $10-50 \mu \mathrm{m}$. They are hardly broken down into primary particles, even at the highest turbulent shear experienced by particles in large rivers. Thus, these are considered to be a major component of sediment dynamics. Microflocs, including primary particles and flocculi, have sizes of $50-200 \mu \mathrm{m}$. Finally, macroflocs are the largest particle structures. They are loose structures with a wide size distribution, ranging from hundreds to thousands of micrometers [9, 10]. Macroflocs are easily broken down when passing through high turbulent shears [8].

Particle size, settling velocity and their temporary and spatial evolution through flocculation, are fundamental properties that need to be estimated to assess sediment transport and deposition processes in space and time. This research focuses on the physical properties of suspended sediment in the fluvial section (Luang Prabang, northern Laos) and in the estuarine part (Song Hau, Vietnam) of the LMR.

\section{Materials and methods}

\subsection{Study area in the fluvial environment (upper limit) and the estuarine environment (lower limit of LMR)}

The field survey in the fluvial upstream domain was conducted during 8 days, from 26 June to 2 July 2017, at the beginning of the wet season. There were neither extreme floods nor low water situations, thus the hydrodynamic conditions were representative of regular 
conditions of flow and sediment transport. Twenty-seven samples were collected in the main Mekong River and its tributaries (Nam Ou, Nam Suang and Nam Khan tributaries). During the survey, hydro-sedimentary conditions were analysed at two cross-sections distance from $\sim 20 \mathrm{~km}$ (Fig. 1a). For each location, samples were collected in 3 vertical profiles (left bank - V1, middle bank - V2 and right bank - V3). In each vertical profile, 3 litres of water sample were taken at various depths $(0 \mathrm{~h}, 0.3 \mathrm{~h}, 0.6 \mathrm{~h}$ and $0.9 \mathrm{~h})$.
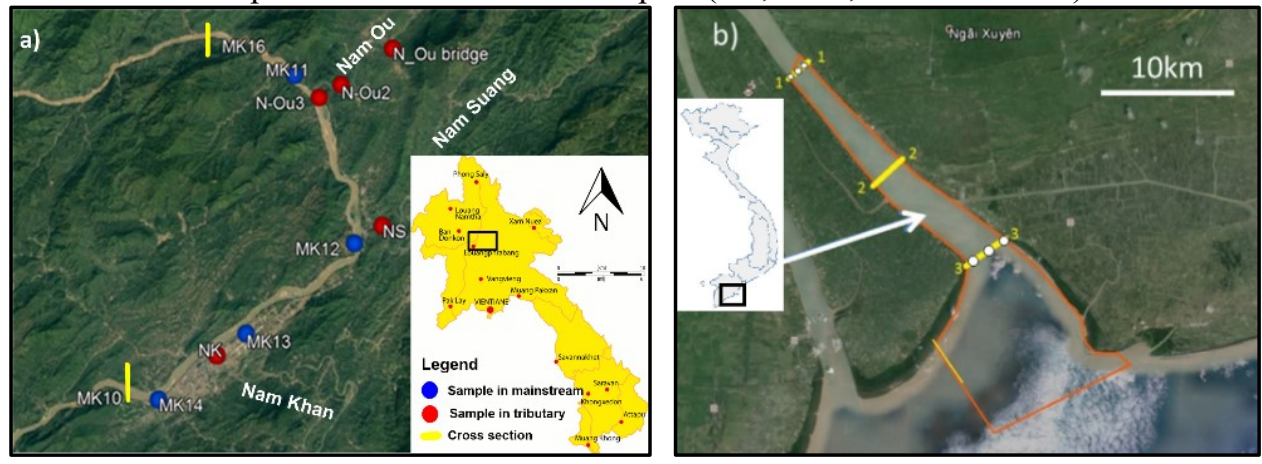

Fig. 1. Sampling sites and locations of the 2 cross-sections in Luang Prabang, Laos [1a] and of the three transects (T1, T2, T3) in the Song Hau estuary [1b]

The study in the estuary was conducted in October 2016 (high flow season). In this survey, three cross-sections (upstream - T1, middle - T2, downstream - T3), at distance of 10 and $15 \mathrm{~km}$, respectively, were chosen to monitor and assess the impact of saline water intrusion on flocculation (Fig. 1b). At each location, samples were taken in three vertical profiles, similarly to the upper limit of the LMB. In total, 243 samples with volumes of 5 litres per sample were collected to investigate the temporary and spatial impacts of suspended solid concentration (SSC) and turbulence on floc properties.

\subsection{Measurement of suspended sediment properties, hydrodynamics and physico-chemical parameters}

As the biggest particles may be easily fragmented by turbulence during transport, in-situ measurement of the particle size distribution (PSD) is required. A LISST-Portable XR instrument (C) Sequoia Scientific, Inc [11]) was used to measure the PSD as soon as possible after sampling. Each sample was measured in two steps, before and after two minutes of sonication. Hence, it is possible to evaluate the proportion of sand and flocs because large-size particles built by smaller cohesive particles (silt or clay) are dispersed by sonication [12].

The SCAF instrument (System for the Characterization of Aggregates and Flocs), was used to measure the settling velocity of particles $[12,13]$. It is an optical settling column, equipped with a vertical array of sixteen optical sensors, each separated by one $\mathrm{cm}$. Measurements taken in the eight upper centimetres provided an estimate of flocs' settling velocity under quiescent conditions $\mathrm{w}_{s, q}$. Measurements made in the eight centimetres near the bottom of the settling tube provided an estimation of settling velocity after flocculation under settling dominated conditions, the latter velocity being $\mathrm{W}_{s, \neq}[12]$.

Some runs were performed in the laboratory under controlled turbulent conditions to complement in situ observations. In total, nine samples were properly acquired in the fluvial environments for contrasted suspended solid concentration (SSC) values varying from $\sim 20$ to $\sim 1,200 \mathrm{mg} / \mathrm{l}$. Five of them were turbid enough to assess sediment settling velocity. In the estuarine environment, nineteen samples were tested for SSC values between $\sim 20$ and 99,000 mg/l (Fig. 3). 
During each monitoring period, the Acoustic Doppler Current Profiler (ADCP), Hydrolab probe (a type of multiprobe instrument measuring in-situ water quality parameters), SSC measurements and EUTECH (a water quality instrument) were utilized to control hydrodynamic conditions, suspended solid concentration and physico-chemical parameters such as turbidity, temperature, $\mathrm{pH}$, ORD, EC, salinity, etc. The full dataset is not presented in this paper, which focuses on particles properties.

\section{Results}

\subsection{Particle size distribution}

\subsubsection{Particle size distribution in Luang Prabang}
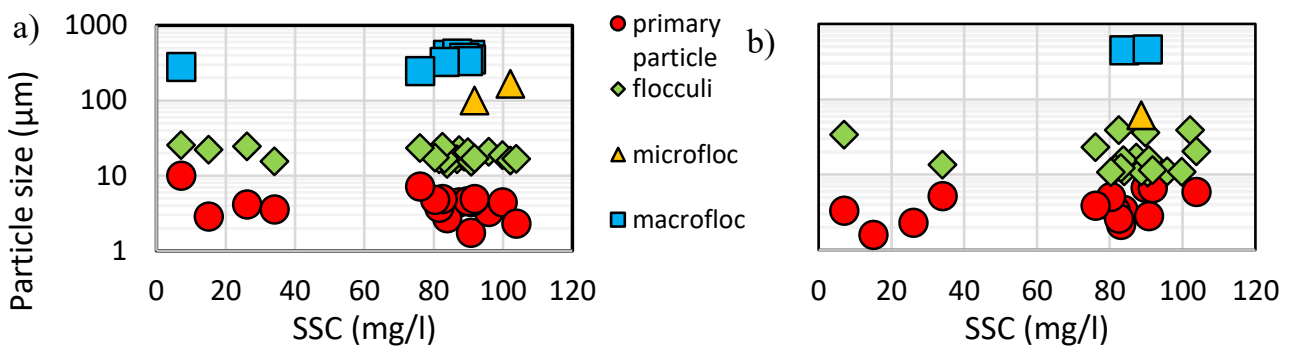

Fig. 2. Variation of particle size classes with SSC (a) before and (b) after sonication

Fig. 2 presents the PSD of particle populations with a variation of SSC before and after sonication. The group of low SSC $(<40 \mathrm{mg} / \mathrm{l})$ is representative for the Mekong tributaries and the group of higher SSC ( $>60 \mathrm{mg} / \mathrm{l})$ is representative for the Mekong main river. Fig. 2 (a) shows the results before sonication. On average, the primary particles accounted for $37 \%$ of the total particle population (in volumetric concentration). The predominant population was flocculi, with a volume concentration of approximately $46 \%$. Microflocs and macroflocs were less represented and accounted for $3 \%$ and $14 \%$ of the total volume, respectively. The macro-flocs size reached a median diameter of $422 \mu \mathrm{m}$. Fig. 2 (b) shows the PSD plot after 2 minutes of sonication. The sonication broke up particles so that the percentage of primary particles, flocculi and microflocs increased to $51 \%, 41 \%$ and $2 \%$, respectively. The contribution of the macroflocs population remained at approx. $6 \%$. These coarsest particles were not broken up by sonication, which indicates the presence of sand. The samples of the tributaries in Luang Prabang had similar PSDs than the ones in the mainstream, except for the sample of Nam Ou bridge. After sonication, PSD of this sample still exhibits high values, with a maximum diameter of $347 \mu \mathrm{m}$. It means that this water sample contains predominantly sand (in agreement with visual observations in the field). A detailed examination of PSD before and after sonication confirmed that samples in Luang Prabang consisted of both cohesive sediment and sand particles.

\subsubsection{Comparison with the particle size distribution in the estuary}

The PSD measurement shows the median size of sediment particles in the fluvial section is $13-23 \mu \mathrm{m}$. In their recent study, [12] were in agreement with the PSD results measured by $[6,7]$. The dominant particle population in the estuary was flocculi, accounting for $80-100 \%$ of the total volume with a median size of $10-15 \mu \mathrm{m}$. In all samples, sand was not in suspension, it was only found in bottom sediment samples. 


\subsection{Settling velocity}

Fig. 3 (a) presents the variation of sediment settling velocity with suspended sediment concentration for both fluvial (white circles) and estuary (blue circles) environments. At low sediment concentrations, settling velocities were approx. $0.01-0.02 \mathrm{~mm} / \mathrm{s}$ in the estuary and a bit higher $0.02-0.08 \mathrm{~mm} / \mathrm{s}$ in the fluvial environment at Luang Prabang. For both upstream and downstream sites, settling velocity increased with SSC because of flocculation. Even if there are only five SCAF samples for the fluvial environment, the two curves exhibit similar trends. The main difference is that the flocculation process seemed to appear at a lower concentration in the river $(\sim 20-30 \mathrm{mg} / \mathrm{l})$ than in the estuary $(\sim 200-300$ $\mathrm{mg} / \mathrm{l})$. In the fluvial environment, the threshold for flocculation was reached for SSC values between 0.1 and $1 \mathrm{~g} / \mathrm{l}$ (settling velocity in the range of $0.1-0.5 \mathrm{~mm} / \mathrm{s}$ ). This threshold was reached at higher sediment concentrations of $3-5 \mathrm{~g} / 1$ in the estuarine environment (slightly higher settling velocity, in the range of $0.4-0.7 \mathrm{~mm} / \mathrm{s}$ ). The efficiency of flocculation was higher for the estuarine environment $(+60 \%$ of increase of the settling velocity) than for the fluvial environment $(+7 \%$ of increase).

Concerning the flocculation index, laboratory experiments conducted with sediment samples from the river show a high variability, but even in fresh water (fluvial environment, grey circles in Fig. 3b), flocculation by differential settling under quiescent condition was observed. The measured flocculation indexes range from 1 to 3 , slightly lower than that measured in the estuarine environment.
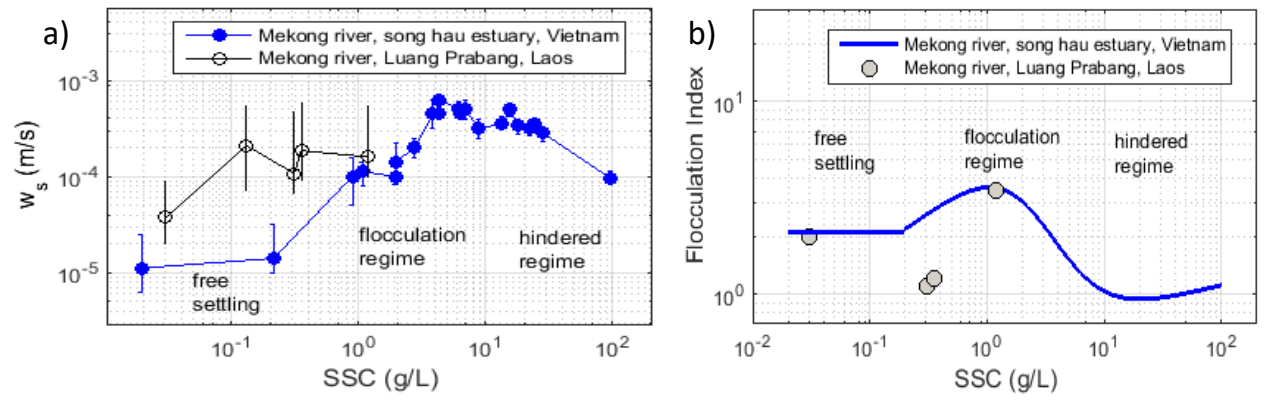

Fig. 3. Sediment properties in the Mekong River to Ocean Continuum. a) Variation of settling velocity with SSC. b) Variation of the flocculation index with SSC

\subsection{Hydraulic conditions in fluvial and estuarine environments}

Shear velocity was computed using the ADCP velocity profile measurements, with the assumption that the inner zone of the profile follows the well-known logarithmic profile [16]. The computed shear velocities were $0.03 \mathrm{~m} / \mathrm{s}$ for the MK10 and $0.04 \mathrm{~m} / \mathrm{s}$ for MK16. The difference between the two cross sections may be explained by the geometry of each cross section, MK10 being wider than MK16.

The Rouse parameter (Ro) gives the balance between the upward turbulence forces $\left(\mathrm{u}^{*}\right)$ lifting the particles and the gravitational force applied on the same particles in a river stream [17]. Here, the diffusion factor $\beta$ is assumed to be equal to one [18]. The Ro value is calculated from estimates of PSD and settling velocity with LISST and SCAF instruments, respectively. For the settling velocities computed with the SCAF (Fig. 3), Ro values at MK10 and MK16 range between 0.002 and 0.007, which corresponds to the washload regime. Hence, particles are presumably transported over long distances, without any interaction with the riverbed. The main PSD mode of the MK10 and MK16 samples analyzed with the LISST is approximately $18 \mu \mathrm{m}$, corresponding to a settling velocity of $0.3 \mathrm{~mm} / \mathrm{s}$ by applying the Stokes settling law. This leads to Ro value of approx. 0.01, 
corresponding to a strong suspension regime. The same Ro value was found by applying the Rouse parameter on the concentration samples from the vertical profiles (Fig. 4).

Few sand particles are present in the MK10 and MK16 cross section samples, with Ro values of $0.75-4.6$. Its means that the very fine sand particles are strongly linked to the water depth, leading to a low suspension regime. As for the coarser fraction, the river flow was not able to transport it in suspension.

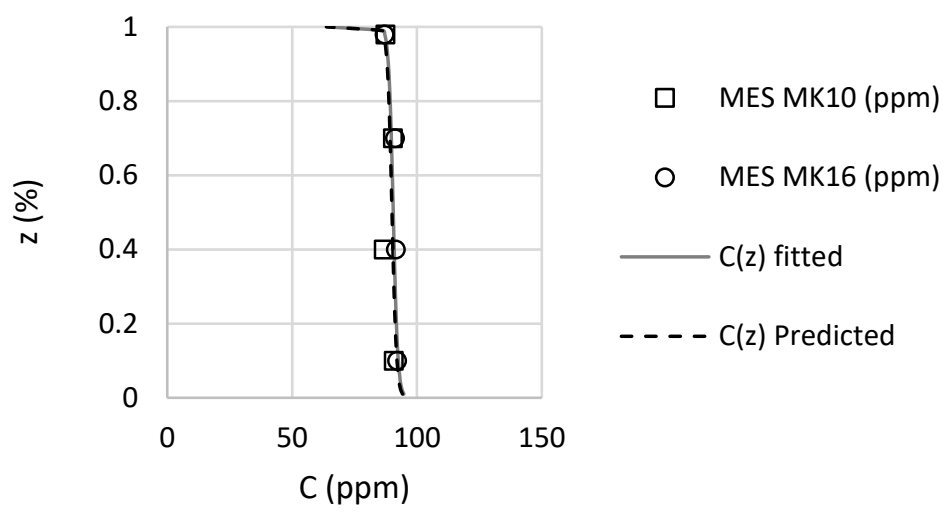

Fig. 4. Vertical concentration distributions at MK10 (squares) and MK16 (circles). The gray line represents the Rouse profile fitted on the concentration values. The black dashed line corresponds to the predicted Rouse profile considering the flow conditions and the main mode of the LISST PSD

In the estuarine environment, the mixing between freshwater from land and salt water from the ocean generates a complex situation, with the formation of vertical stratifications in the water column. This was clearly observed during our field survey in October 2016 (graph not shown), and was also reported by [12] from field surveys conducted in December 2015 and March 2016 (Fig. 2 of their paper). In such conditions, a vertically integrated Rouse number has no meaning. Numerical modelling is the only tool able to combine sediment and hydrodynamic interactions to estimate the overall budget of sediment in the estuarine zone. A global numerical exercise was recently conducted by [19], who concluded that the estuarine environment of the Mekong delta is mainly trapping sediments (flocculi, micro-flocs, macro-flocs and sand), even if some large redistribution occurs, in link with the convexity of the coast in river mouths.

\section{Discussion}

The PSDs from both fluvial and estuarine environments are gathered in a triangle sketch in Fig. 5. Before sonication, most of the particles were flocculi with average contribution percentages of $77 \%$ and $70 \%$, respectively (Fig. 5a). After sonication, the PSD displayed an increased number of primary particle class for both samples taken in the Mekong delta and Luang Prabang (16 - $26 \%$ to 60 - $65 \%$, respectively) (Fig. 5b). These figures also show a wider variety of particle sizes in the Mekong delta (blue triangles) than in Luang Prabang (red squares).

Fig. 6 displays the detailed PSD for 9 representative samples in the fluvial and estuarine environments. Each time, the PSD before sonication is followed by the one after sonication. It illustrates the large variation of particle sizes in the delta, predominantly 10 $386 \mu \mathrm{m}$ before sonication and in the range of $2.21-331 \mu \mathrm{m}$ after sonication. It is clear that sand appears in the Mekong delta with a percentage of $11 \%$ for a median diameter of $>300$ $\mu \mathrm{m}$. In contrast, the particle size in Luang Prabang was much smaller with a predominance of primary particles and flocculi. 

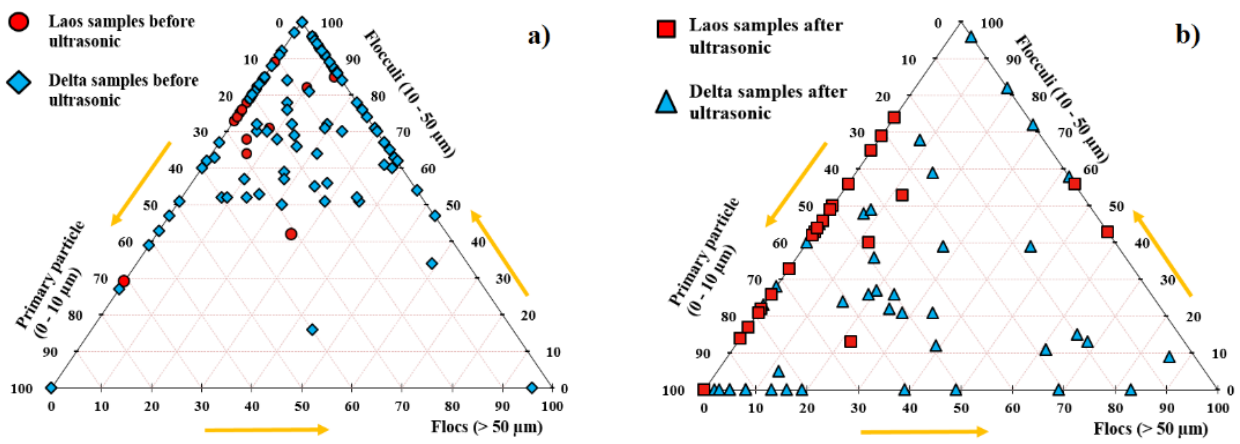

Fig. 5. Triangles of PSD in the upper part and estuary analysis (a) before and (b) after sonication
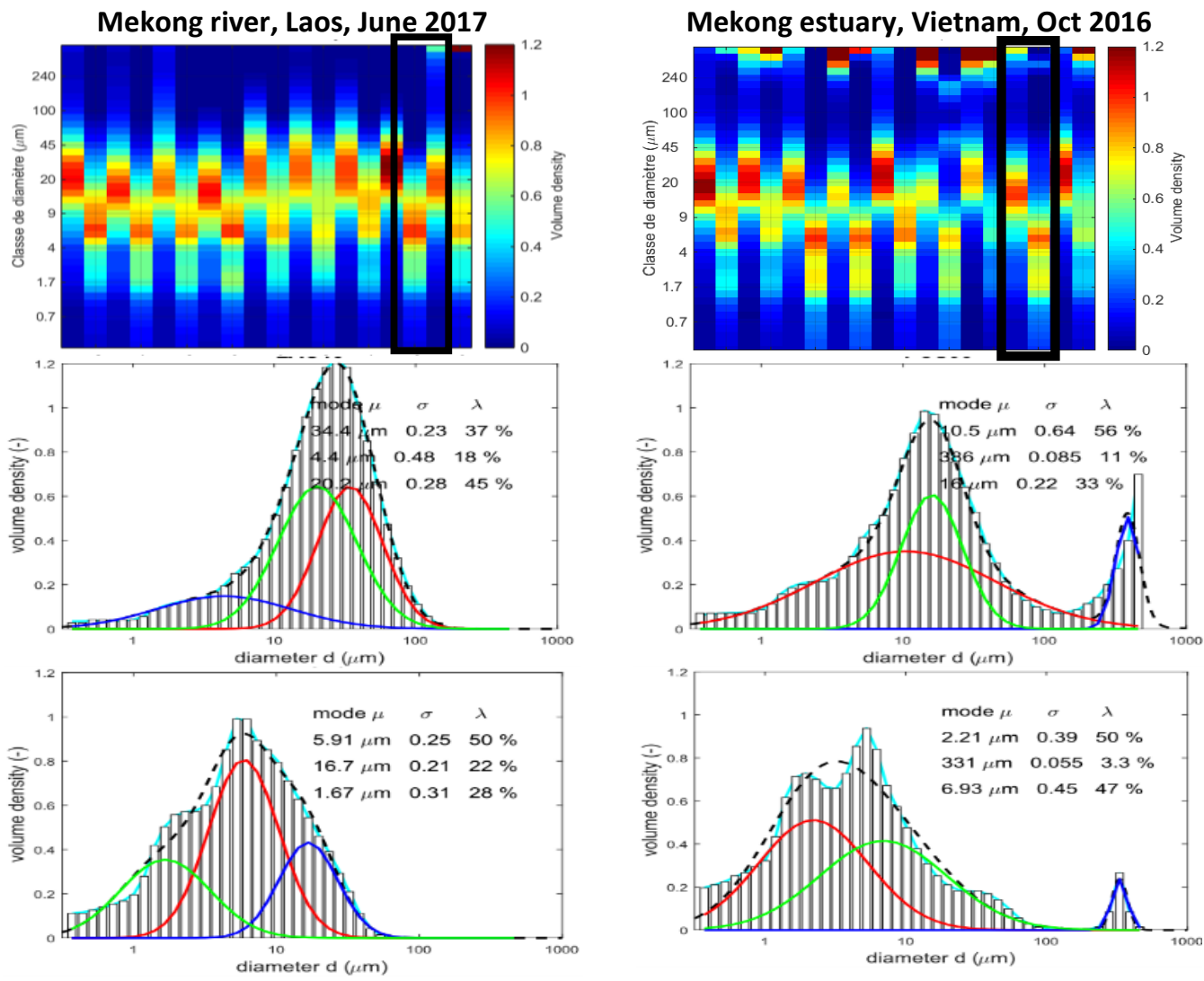

Fig. 6. The PSD in 2 representative samples in the fluvial (left) and estuarine (right) environments

\section{Conclusion}

Field surveys and laboratory analysis performed in the upper fluvial and lower estuarine environments provide the first intercomparison of the main sediment properties in the LMR. These preliminary results show that flocculation processes take place in both upstream and downstream environments, with the existence of 4 particle classes, but with different proportions. While most of the particles in the upstream part of the Mekong were primary particles and flocculi (92\%), the downstream results showed higher percentages of microflocs and macroflocs, also with the appearance of sand (diameter of $>300 \mu \mathrm{m}$ ). 
SSC in the Mekong River ranged from 7 to $110 \mathrm{mg} / \mathrm{l}$ in the mainstream at Luang Prabang, and the vertical distribution in SSC did not vary significantly between two sites, 87 - $92 \mathrm{mg} / \mathrm{l}$. Oppositely, the SSC in the estuary showed a high fluctuation, $0-5 \mathrm{~g} / \mathrm{l}$. The settling velocities in the river and in the estuary present similar variations. At low SSC, settling velocities were $0.01-0.02 \mathrm{~mm} / \mathrm{s}$ in the estuary, lower values $(0.02-0.08 \mathrm{~mm} / \mathrm{s})$ were observed in the river. For both upstream and downstream sites, the settling velocity increased with SSC because of flocculation and differential settling.

Rouse number calculated from SCAF and LISST data clearly show that flocculi are transported in suspension or even as washload. It means that a predominant part of the primary particles and flocculi populations could reach the estuary without physical transformation. This explains why PSD of both estuarine and fluvial environments are quite similar for these populations of particles.

However, the upstream dynamic is affected by the topographical conditions and tributaries, while, in the estuary, it is controlled by the permanent interaction of fluvial and marine waters. For this reason, some realistic numerical predictions of sediment dynamics at a regional scale would require further monitoring in both upstream and downstream sections of the Lower Mekong River.

\section{Acknowledgements}

The authors would like to thank the Université catholique de Louvain, Belgium for Hoang-Anh Le's doctoral fellowship, the Institut de recherche pour le développement, France for supporting the field survey in Laos and the Lower Mekong Delta Coastal Zones project for sharing data on the estuary.

\section{References}

1. Mekong River Commission portal, available at http://www.mrcmekong.org/

2. S.E. Darby, C.R. Hackney, J. Leyland, M. Kummu, H. Lauri, D.R. Parsons, R. Aalto. Nature 539, 4 (2016)

3. J.D. Milliman, R.H. Meade. Journal of Geology 91, 21 (1983)

4. R. J. P. Schmitt, Z. Rubin, G.M. Kondolf. Geomorphology 294, 12 (2017)

5. C. Peteuil, T. Frétaud, C. Wirz, B. Camenen, L. Guertault, J. Le Coz, G. Dramais. In Proceedings of the 19th IAHR-APD Congress (2014)

6. E. Wolanski, N.N. Huan, N.H. Nhan, N.N. Thuy. Estuar. Coast. Mar. Sci. 43, 18 (1996)

7. E. Wolanski, N. H.Nhan, S.Spagnol, J. Coastal Res. 14, 13 (1998)

8. J. Manning, J.V. Baugh, J.R. Spearman, R. Whitehouse. In Sediment Transport (2011)

9. J. Lee, M. Fettweis, E. Toorman, F.J. Molz. J. Geophys. Res.: Oceans 117, 17 (2012)

10. M. Fettweis, F. Francken, V. Pison, D. Van den Eynde. Mar. Geol., 235, 12 (2006)

11. Sequioa. LISST-Portable|XR User's Manual Version 1.2 (2016)

12. N. Gratiot, A. Bildstein, T.T. Anh, H. Thoss, H. Denis, H. Michallet, H. Apel. Comptes Rendus Geoscience 349, 9 (2017)

13. N. Gratiot, C. Coulaud, C. Legout, B. Mercier, H. Mora, V. Wendling. PatentPublication number WO2015055963 A1 (2015)

14. B. Camenen, J. Le Coz, G. Dramais, C. Peteuil, T. Fretaud, A. Falgon, S. A. Moore. In Proc. River Flow conference, 8 (2014)

15. D.J. Nowacki, A.S. Ogston, C.A. Nittrouer, A.T. Fricke, P.D.T. Van. J. Geophys. Res. Oceans 120, 21 (2015)

16. L.C. Sime, R.I. Ferguson, M. Church. Water Resour Res 43, 3 (2007)

17. W.C. Rouse. U.S. Patent and Trademark Office (1938)

18. L. Van Rijn. J Hydr Eng Div 110, 1613 (1984)

19. P. Marchesiello and D.C. San. Report of the contract AFD-SIWRR 2016 (2017). 